\title{
Re-Look at Local Design: Discussion on Sustainable Innovation of Oriental Design
}

\author{
Chunlei Chai ${ }^{\mathrm{a}, \mathrm{b}, 1}$ and Ruiyi Cai ${ }^{\mathrm{a}}$ \\ ${ }^{a}$ Modern Industrial Design Institute, Zhejiang University, Hangzhou, China \\ b State Key Laboratory of CAD\&CG, Zhejiang University, Hangzhou, China
}

\begin{abstract}
Oriental Design is recently one of the most significant theoretical fields in design research in China. For a long time, related research has been controversial due to the complicated historical ambiguity, but today's researchers are able to reshape Oriental Design with brand-new materials and independent perspectives. This is an opportunity of the times and a strategic topic for local design research. This article specifically explores the sustainable innovation value and significance of Oriental Design, puts forward its internal connections and commonalities, and supports it with the analysis of sustainable innovation levels to provide support for the development of Oriental Design.
\end{abstract}

Keywords. Design innovation, oriental studies, sustainable design, transformation design, system design

\section{Introduction}

The modern design philosophy dominated by the West can be traced back to the "Three Greeks" in the Golden Age of Athens. In contrast, Eastern Design is an area that has only received attention in design research in recent years. The proposal of the topic of Oriental Design (OD) reflects the awakening of Oriental self-cultural consciousness [1]. This is closely in line with the development of the times. The image of the East is changing from being "shaped by others" to "shaped by oneself" [2], and design has become an effective participation force of human cultural orientation. OD research is not only the protection of the diversified academic ecology under the wave of globalization [3], but also the recognition of the local thinking system of OD researchers. It enables us to seek answers to questions completely from the perspective of local needs. The in-depth study of OD is regarded as one of the most significant events in the development of design studies in China in recent years [4]. It is one of the core strategic issues that must be faced in the process of constructing local design theory.

OD is rooted in Oriental philosophy. Although "Oriental Studies" has always been an important field of cultural studies [5], it has many vague and prejudiced definitions due to long-term extensive and complex historical and political influences [3]. The controversy raised by researchers for its ambiguity, fragmentation, and relativity [4] not only reflects the limitations of history, but it should be noted that with the closer cultural exchanges, researchers are constantly facing and updating their knowledge of things.

\footnotetext{
${ }^{1}$ Chunlei Chai. dishengchai@126.com
} 
This developmental attitude and basic cognition to solve current problems are the innovation core of OD.

Therefore, this article intends to discuss the sustainable innovation value and potential of OD. Although this discussion is preliminary, it is hoped to provide support for the development of OD, and discuss and theoretically verify the misunderstandings and disputes in it. After summarizing the history and research content of Oriental Studies and Oriental Design, this article discusses the typical misunderstandings of OD's innovation from three dimensions in Chapter 4 and elaborates them one by one. The summary is as follows: 1) Research on design methods rather than just design styles; 2) Contemporary advancement rather than just returns to history; 3) Pursue the universality of civilization rather than just cultural personality. Finally, the article discusses the concepts of sustainable design innovation in OD, and analyzes and verifies it based on the recently proposed sustainable innovation level framework.

\section{Historical Development: Oriental Studies and Oriental Design}

East-West exchange is the highlight of the development of human civilization. It has made the material achievements of mankind in the past 100 years exceed the total of all history. In the history of design after the fifteenth century, regular cultural exchange trends can be found, such as the "Chinese style" or related trends that erupted every 50 to 100 years in modern Europe. "Orientalism" can sometimes even have a decisive influence on the field of modern design [6], such as: Japanese Ukiyo-e's revolutionary ideas for modern art, and the ecological concepts and the basic principles of ergonomics brought by the ancient Chinese furniture system to modern home design. The unique personality of culture and the innovation inspired by communication have brought leapforward development for mankind. Oriental Studies was born and developed in the context of cultural exchanges between the East and the West, and its content and trends reflect the changes of the times.

"Oriental", originally meant to refer to the place where sunrise, generally refers to the place east of the location. Both the concepts of "Oriental" and "Oriental Studies" were very vague when they were put forward [3], and their meanings have undergone tremendous changes with the exchange of global civilizations. Take the Oriental concept in the history of modern design as an example: geographically, it includes Near East, Middle East, and Far East [6]; culturally, it occupies three representative cultures, which is Indian, Arab and Chinese culture [7].

The "Oriental Studies" in history is vague and complicated [3, 4], also because the concept of the Oriental is geographically too broad. Researchers usually determine the research perspective based on their own knowledge. Since Edward Wadie Said's "Orientalism" in 1978 first introduced this theme, various controversies have continued. For example, although Said criticized the cultural prejudice against Asia and the Middle East [8], the research scope of "Orientalism" proposed by him is only in the Middle Eastern cultural circle mainly based on India and Arabia [9]. And what he explained is only an artificially constructed existence that opposes the Western discourse system, rather than a natural "Oriental" existence. In "The Aesthetics of the East", Tomonobu Imamichi focuses on the history of the development of aesthetic thoughts in China and Japan. While Shuming Liang focused his Oriental Studies on China and India in his two works: "Eastern and Western Cultures and Philosophy" and "An Overview of Oriental Academic Studies". This is the limitation brought about by the unclear vision of 
globalization, but it also reflects that "Oriental Studies" is a comprehensive discipline based on contemporary needs and the development background of global civilization. Its connotation and focus keep pace with the times. After the two world wars [3], with the increasingly transparent global cultural exchanges and the diversified development of civilizations, "Oriental Studies" has increasingly shown its comprehensiveness, intersectionality and expansibility.

Therefore, OD with this background has a strong design modernity, and its focus is constantly updated with the current development of the Eastern world. Doudou Chen's research [9] proposed that the recent research scope of OD can focus on the leading regions of local design development, namely China, Japan, and South Korea.

In 2018, the topic of "Oriental Design Research" became a Major Nationalsponsored Social Sciences Funding Program in China [4]. It is an inevitable strategic exploration of China after the continuous development of society, economy and culture, and it is also the core problem that must be explored in the construction of the theoretical system of Chinese design studies.

\section{Overview of Oriental Design Research}

Oriental Design is the science of OD behavior. Its core is Oriental material culture and its craftsmanship [8]. The starting point and attribution point of the research are Oriental culture and philosophy $[8,10]$. Its research branches include design primitive theory, design epistemology, design methodology and design application theory [11]. From the perspective of the history and design practice, the research of OD is to understand the advanced development trends of the Oriental world in which we live through creation and communication. It is a divergent discipline based on social dynamic development, emphasizing the integration of theory and practice, and aiming at innovation.

In the cultural structure, the artifact culture represented by the product is the easiest to reflect changes, while the institutional culture and philosophical values are relatively stable [12]. Oriental philosophy is the core of OD methodology, which is enlightened by people's views and understanding of agriculture. Oriental philosophy represented by China has put forward key thinking on the following three issues [7]: 1) the relationship between man and nature; 2) social relationship, 3) the conflict and balance of human emotions.

Therefore, respect for nature, emphasize the harmonious cosmology and environment view of the unity of nature and man; fully affirm the power of morality in society, respect harmony and humility in the way of doing things; take tranquility and calmness as the aesthetics of personal life - is the unique starting point of OD $[10,12]$.

Oriental creations rooted in Oriental philosophy show respect and love for the nature, care for people, and love for creation in spiritual concepts, which are consistent with the pursuit of modern design. OD emphasizes the spiritual connotation of the beauty of harmony and the implementation rules of the beauty of form. Specifically, which is, in terms of design concepts, it pursues the coordination of products and environment, humans and nature, and avoids excessive design; in design techniques, it is good at condensing, abstraction, symbolism, imitation, and analogy; in the aesthetic style, it highlights elegance, subtlety, suggestion, simplicity, practicality, and meticulous work $[10,12-14]$. 


\section{Discussion on the Misunderstanding of Oriental Design Innovation}

This chapter discusses the most controversial misunderstandings about the innovation concepts of OD from three dimensions and discusses accordingly, and finally summarizes the three-dimensional framework of the innovative development of OD, as shown in Figure 1.

\subsection{Research on Design Methods Rather Than Just Design Styles}

Researchers have long emphasized $[4,12,15]$ that the study of OD should not only be understood as the application and continuation of traditional cultural symbols and design styles, but should be based on a holistic, systematic, and aesthetic spirit. From the perspective, without being constrained by concrete forms, expressing the inner spirit and cultural will with design, and integrating the Oriental philosophical and cultural thoughts into the modern world design trend, can we maximize the contemporary OD value.

Intuitively, the design styles of the East and the West are different. For example, the East is more introverted and the West is more extroverted; the East pays more attention to the group, and the West pays more attention to the individual. However, in-depth study of this kind of preliminary understanding will often encounter counterexamples. Therefore, a distinction of design styles directly by region will obscure the real research issues and value demands. Like the key issues raised by Xiaofeng Fang in his research [1]: Looking back at the labeling understanding or various definitions of OD in modern times, how many are due to cultural differences at the core level? How many are due to the technological gaps? Therefore, the superficial research and application that only focus on design elements is not enough to cover the research content.

The expression of OD does not lie in whether its design elements are "Oriental", but from the methodology, that is, whether it derives from the expression of Oriental philosophy in terms of the perspective of problem analysis and the method of problem solving. Therefore, OD is not just a concept to explore design styles[9], but a whole design paradigm derived from the current and actual Oriental life practice to express the oriental humanistic outlook and design concepts.

\subsection{Contemporary Advancement Rather Than Just Returns to History}

The concept of "Oriental" evolves with time, so the connotation of OD should obviously also be defined in the current and realistic context [1]. Historical retrospective research is necessary, but this does not mean "tradition return". Because history exerts its value in its influence on the present, what needs to be faced is also the social problems of today $[1,9,11]$. This should be the basic understanding of OD Studies.

Looking back at the "Oriental products" that have profoundly influenced global human civilization in history, whether it is the four great inventions, porcelain, or the philosophy and aesthetics of the East, they were all highly advanced at the time. A design that can be recognized across cultures must have the advanced nature of the times and have "rational and mature cultural concepts" [9].

Therefore, OD is an exploration facing the current and realistic problems. Its goal is to obtain the optimal solution, and it is not important to draw materials from historical and current cultures. The final design result should be applicable to the present and adapt to contemporary advanced technology. OD is a reflection and construction of the future 
oriental aesthetics and lifestyle [15], based on the local society, pointing to an innovative future.

\subsection{Pursue the Universality of Civilization Rather Than Just Cultural Personality}

OD inevitably endows design with "Oriental" personality and particularity. In modern history, the "Oriental" right to speak originated from the artificial creation and relationship mapping of the "West" to the "non-Western" [3]. It exists as a specialty outside the system to fulfill the need for reflection or criticism within the system. This particularity has the significance of the times, and it also has its limitations.

However, the personality of design is of great significance. Cultural personality originates from the fundamental temperament of a nation, and has irreplaceable universal value and spiritual charm [9]. The formation of a kind of cultural personality is the result of the spiritual and material creation of all individuals in a nation. Not only did they complete their cultural self-knowledge, but they also received the recognition and admiration of other cultural forms. Therefore, the personalization of design and the use of local cultural elements to participate in the creation and reshaping of global culture have played an important role in maintaining the diversification of design and avoiding the homogenization brought about by the impact of modern Western design context [3]. With this as a starting point, OD enables the "Orient" to actively participate in cultural orientation with the power of design, and from the standpoint of the "Orient" itself, it integrates the personality of OD into global cultural values. Therefore, the full personality and particularity are the prerequisites for its universality.

And universality is the in-depth requirement and development trend of design personality. First of all, the East and the West are not dualistic, and the culture is not exclusive. OD can only reflect and evolve its meaning if it participates in the evolution of the current global civilization. And only when the design personality is sufficiently inclusive, innovative, and is able to flexibly absorb, transform, and expand in different contexts [9], can it transcend the specific limitations of the "Oriental" and move toward universality. Only then can it be accepted by other cultural forms, and has universal significance and value for solving problems encountered in the development of human society. OD should be based on the personality of the Oriental culture, and the universality of civilization as the pursuit and self-assessment index.

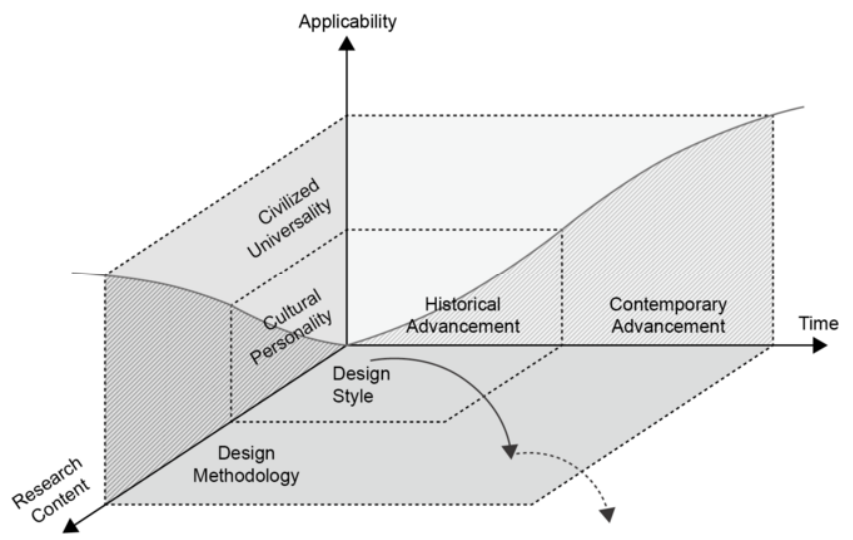

Figure 1. The three-dimensional framework of the innovation and development of Oriental Design. 


\section{Discussion on Sustainable Innovation of Oriental Design}

\subsection{Commonness of Oriental Design and Sustainable Innovation Theory}

\subsubsection{The Thinking Mode of "Circulation Theory"}

The origin of traditional Oriental philosophy in China is closely related to farming culture. For example, Yuqing Zhang et al. put forward: "Chinese farming culture is the life root of OD, and the Chinese philosophical thought extended from farming culture is the inner soul of OD."[10] Therefore, Oriental philosophy contains many reflections on material and spiritual issues related to agriculture. Among them, the understanding of natural ecology is particularly prominent-specifically manifested in the formation of the concept of a thinking system with the concept of "circulation" as the core [16]. From the process of agricultural production, based on the observation of the change of natural life, the Chinese have summed up the thinking mode of "Circulation Theory", which includes the philosophical understanding of natural elements, categories, laws, reactions, evolution, etc., forming a sustainable "circular" cosmology of interlocking, cyclical, endless, change and innovation.

Many OD researchers have mentioned the design concept of "respect for nature, emphasizing that man and nature are a community of life and need to be organically combined" $[8,10]$. However, this aesthetic pursuit of "natural design" is actually only a manifestation of the design method of OD. Tracing back to the source, this stems from the fundamental personal values of "the unity of man and nature", and a "recycling" cosmology. Chinese philosophy advocates innovation and change to create a better life, but it also sets a basic framework for human behavior to guide changes in conformity with a sustainable system of "recycling", ensuring that they are not excessive and cause "destructiveness" load to the system. This "moderate and harmonious" survival wisdom has great reference value for solving the "complex system" design problems of modern society, and it coincides with the sustainable design concept that has attracted much attention today.

\subsubsection{System-level Innovation Transformation}

In addition, OD takes innovation as its ultimate goal [11], so it has focused attention and a unique thinking framework in the field of design innovation at the system level. This echoes the core topic of sustainable design research in recent years - the theory of social technological system transformation guided by system innovation.

Firstly, in Chinese philosophy, the holistic view of everything is the basic concept, and this understanding is integrated into the spirit of the Orientals. Therefore, many cultural differences studies have recognized that the Orientals are better at using a holistic way of thinking, while the Westerners are better at using linear logic to pursue the answer [16]. Secondly, the integration of different ethnic groups and different cultural circles in history [2] created the special absorption power of the diversified integration of Chinese culture. For a long time, the process of effectively collecting and using design elements from different sources has promoted the development of systematic and integrated thinking and skills of designers. And the way of thinking that focuses on the law of movement, the integrity of the development and evolution model, and the conceptualization, in today's diversified society where social and technological system variables are increasing day by day, will be more suitable for generating fundamental and breakthrough innovations. 
On top of this, the unique significance of OD is that it focuses on the research of local-based social technology system innovation strategies. Today's OD can get rid of the "artificially abstract and imaginary Orient", and become design research that starts entirely from the "here and now". Based on the unique charm and advanced humanistic values, it forms an innovative design paradigm that integrates contemporary technology and faces the future oriental society.

\subsection{Level Analysis of Sustainable Innovation of Oriental Design}

In the current relatively complete review of sustainable design published in the authoritative journal "Design Studies" in the field of design research, Ceschin and Gaziulusoy proposed a development framework in the field of sustainable innovation [17] - sustainable design approaches are categorized into four different innovation levels: Product innovation level, Product-Service System innovation level, Spatio-Social innovation level and Socio-Technical System innovation level. The logic of its evolution has evolved from the earlier product-centric approach, gradually expanding the scale to design innovation at the system level, and taking the development of the times as the axis to continuously transform.

Based on this recent framework, the sustainable innovation level of OD is analyzed. Due to the limited amount of research in the field, a dot matrix is used for display, as shown in Figure 2 and Table 1.

Firstly, according to the relatively even distribution of sustainable innovation levels, it can be proved that the current research depth of OD has considerable innovative advancement and value potential. Secondly, in terms of the specific development situation, the sustainable innovation level of OD has shown a significant growth trend in the number and depth of research, especially during the explosive growth period of 20152019. This is in line with the National-sponsored Social Sciences Funding Program of OD in 2018. After 2019, the number and depth of the literature have fallen, and there is still plenty of room for future research. Third, the current levels of sustainable innovation in OD studies are more distributed at the Product, Spatio-Social, and Socio-Technical innovation levels, but there are gaps in the Product-Service level. This "U" structure is related to the immaturity of the discipline: between the research on product design at the surface level and the discussion of the systematic conceptual model at the top level, there is an urgent need for backbone research forces to support. This structural deficiency is worthy of attention, and related research urgently needs to be filled.

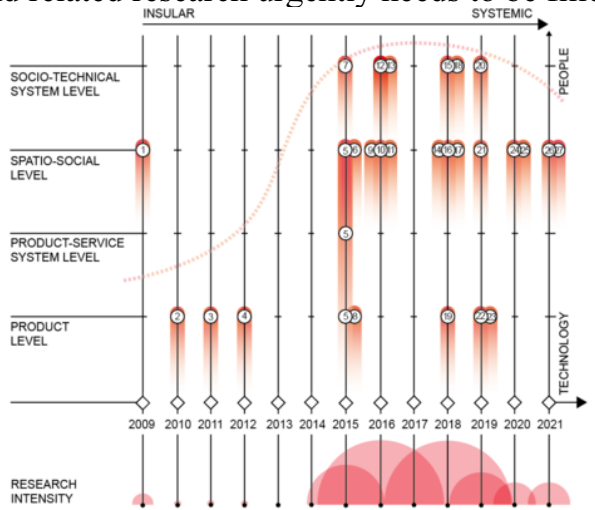

Figure 2. Analysis of sustainable innovation levels of Oriental Design based on the four-tier framework.

* Research Intensity $=\Sigma$ (Number of studies * Sustainable innovation level) 
Table 1. An overview of research on Oriental Design in recent years corresponding to Figure 2.

* The serial numbers (No.) in Table 1 correspond to the numbers in Figure 2

\begin{tabular}{|c|c|c|c|}
\hline No. & Year & Researchers & Key research points \\
\hline 1 & 2009 & Jinghao Li & $\begin{array}{l}\text { Differences between Eastern and Western cultures and } \\
\text { modern design concepts }\end{array}$ \\
\hline 2 & 2010 & $\begin{array}{l}\text { Xiaolong Fu and } \\
\text { Nana Yang }\end{array}$ & Oriental logo design \\
\hline 3 & 2011 & Juan Zhao & $\begin{array}{c}\text { The influence of oriental art on the early stage of } \\
\text { modern design }\end{array}$ \\
\hline 4 & 2012 & Geng Chen & Oriental fashion design \\
\hline 5 & 2015 & Hui Zeng & Oriental Design and oriental Life aesthetics \\
\hline 6 & 2015 & Hai Fang & "New Chineseism" in Oriental Design \\
\hline 7 & 2015 & Xiaofeng Fang & The prejudice and value discussion of Oriental Design \\
\hline 8 & 2015 & Shenshen Wu & Oriental costume design \\
\hline 9 & 2016 & Zhaohui Cheng & Oriental Design education \\
\hline 10 & 2016 & $\begin{array}{r}\text { Xiaoming Shou et } \\
\text { al. }\end{array}$ & Oriental garden design paradigm \\
\hline 11 & 2016 & Bibo Wu & Oriental cultural and creative design paradigm \\
\hline 12 & 2016 & Haiyan $\mathrm{Wu}$ & Definition of Oriental Design \\
\hline 13 & 2016 & Jiadi Yu & $\begin{array}{c}\text { Discussion on Oriental education system in visual } \\
\text { communication }\end{array}$ \\
\hline 14 & 2018 & Lanchun Bian et al. & Oriental garden design paradigm \\
\hline 15 & 2018 & Doudou Chen & Research scope and definition of Oriental Design \\
\hline 16 & 2018 & Zhengda Chen & Oriental Design education reform \\
\hline 17 & 2018 & Zhenji He & The history and current value of Oriental Design \\
\hline 18 & 2018 & Zheng Liu & Oriental Design methodology structure \\
\hline 19 & 2018 & Yali Peng & Oriental element textile design \\
\hline 20 & 2019 & Zhengda Chen & $\begin{array}{c}\text { The reform and restriction breakthrough of oriental } \\
\text { design education }\end{array}$ \\
\hline 21 & 2019 & Chaode Li et al. & Research progress of Oriental Design \\
\hline 22 & 2019 & Lijun Sun & Oriental furniture design \\
\hline 23 & 2019 & Siyan Tao & Oriental folk culture symbol design \\
\hline 24 & 2020 & Weichen $\mathrm{Wu}$ & Oriental regional brand building and self-expression \\
\hline 25 & 2020 & $\begin{array}{r}\text { Wuzhong Zhou et } \\
\text { al. }\end{array}$ & Research progress of Oriental Design \\
\hline 26 & 2021 & Yijun Dai et al. & Research progress of Oriental Design \\
\hline 27 & 2021 & Yuqing Zhang et al. & Oriental landscape design paradigm \\
\hline
\end{tabular}

\section{Conclusion}

This article expounds and supports the unique cultural charm and sustainable innovation value of Oriental Design, through theoretical discussion and combined with the crossstudy of sustainable innovation design framework. It is a design research direction that not only has universal advancement, but also has local cultural characteristics; not only discusses design philosophy, but also pays attention to the combination of practice.

When we talk about Oriental Design today, we have completely different resources and materials from the last century, as well as a clearer and more independent perspective. This is an opportunity of the times for design studies, and it is also a strategic proposition for future development. 


\section{References}

[1] Xiaofeng Fang, The Danger and Value of "Orient". New Art, 2015. 36(04): p. 9-10.

[2] Weichen Wu, Self-shaping and Expression: Regional Brand Construction in the Oriental Visual Context. New Art, 2020. 41(11): p. 89-92.

[3] Zhenji He, "Oriental" and "Design", an era proposition in Chinese design research under the globalization. New Art, 2018. 39(11): p. 74-79.

[4] Chaode Li, Lin Zhu, and Shaoni Meng, 2018: Changes and pains in design research. Chinese Literature Review, 2019(02): p. 49-59.

[5] Zhengda Chen, Limits and Breakthroughs of Visual Communication Design: Teaching Thinking and Practice Based on the Construction of Oriental Design. Journal of Nanjing University of the Arts (Fine Arts and Design), 2019(03): p. 171-174.

[6] Hai Fang, "Oriental", "Oriental Design" and "New Chineseism". New Art, 2015. 36(04): p. 6-8.

[7] Jinghao Li, Oriental Cultural Thoughts and Modern Design Concepts. Art Observation, 2009(10): p. 7879.

[8] Jiadi Yu, Misunderstanding of "Oriental Design" in the Teaching of Visual Communication Design. New Art, 2016. 37(04): p. 13-18.

[9] Doudou Chen, Some Questions about "Oriental Design". New Art, 2018. 39(11): p. 80-83.

[10] Yuqing Zhang, Wuzhong Zhou, and Zhicheng Zhou, Research on Rural Landscape Design Based on Oriental Design. Packaging Engineering, 2021. 42(12): p. 32-38.

[11] Haiyan Wu, Definition of "Oriental Design". New Art, 2016. 37(11): p. 16-20.

[12] Zheng Liu, A Preliminary Study on the Structure of Oriental Design Methodology. New Art, 2018. 39(11): p. 84-86.

[13] Hui Zeng, Oriental Design and Slow Life Aesthetics. New Art, 2015. 36(04): p. 11-13.

[14] Bibo Wu, "The Fate of the Earth, the Way of the Artifacts" Oriental Creation Experiments: Looking back at the design of local themed derivatives from the international exhibition hall. New Art, 2016. 37(07): p. $119-124$

[15] Zhengda Chen, Reform and Construction of Visual Communication Design Education Curriculum System Based on the Oriental Perspective. New Art, 2018. 39(07): p. 126-131.

[16] Zhaohui Cheng, Looking Back to Comprehensive Design Teaching from the Perspective of Oriental Wisdom. New Art, 2016. 37(04): p. 5-12.

[17] Ceschin, F. and I. Gaziulusoy, Evolution of design for sustainability: From product design to design for system innovations and transitions. Design Studies, 2016. 47: p. 118-163. 